\title{
Response to the Letter to the Editor of S. Wang et al. concerning P. Suchomel's Expert's Comment of the Grand Rounds case entitled "Syringomyelia with irreducible atlantoaxial dislocation, basilar invagination and Chiari I malformation", Eur Spine J, Vol 19, no 3, 2010: pp 367-369 (by Shenglin Wang et al.)
}

\section{P. Suchomel}

Received: 6 April 2010/Published online: 18 May 2010

(C) Springer-Verlag 2010

Dear Editor,

I appreciate very much that the discussion around the published case is not finished yet. As I have written in my comment, there is a lack of systematic experience with surgical treatment of CVJ anomalies leading to large variability in the treatment approaches among different countries and surgeon. Nevertheless, I still suppose that the not removed odontoid process can represent an unnecessary risk during the posterior closed reduction maneuver, particularly if done without electrophysiological monitoring. Concerning the additional support of anterior column, I agree with Dr. Wang that odontoid fused with the base can add further anterior support. We also perform anterior cage strut support, but only in cases where extensive bone removal diminishes the load-bearing capacity of anterior and middle spinal columns; however, this was not exactly the case of presented patient. Moreover, as seen on the CT obtained 6 months after the surgery, odontoid-clival fusion was not detected in the reported patient.
P. Suchomel $(\bowtie)$

Department of Neurosurgery, Regional Hospital Liberec,

Husova St. 10, 46063 Liberec, Czech Republic

e-mail: petr.suchomel@nemlib.cz 